\title{
Sensorless Direct Power Control of Induction Motor Drive Using Artificial Neural Network
}

\author{
Abolfazl Halvaei Niasar and Hossein Rahimi Khoei \\ Faculty of Electrical \& Computer Engineering, University of Kashan, Kashan 87317-51167, Iran \\ Correspondence should be addressed to Abolfazl Halvaei Niasar; halvaei@kashanu.ac.ir
}

Received 27 September 2014; Revised 31 January 2015; Accepted 2 February 2015

Academic Editor: Matt Aitkenhead

Copyright (c) 2015 A. Halvaei Niasar and H. Rahimi Khoei. This is an open access article distributed under the Creative Commons Attribution License, which permits unrestricted use, distribution, and reproduction in any medium, provided the original work is properly cited.

\begin{abstract}
This paper proposes the design of sensorless induction motor drive based on direct power control (DPC) technique. It is shown that DPC technique enjoys all advantages of pervious methods such as fast dynamic and ease of implementation, without having their problems. To reduce the cost of drive and enhance the reliability, an effective sensorless strategy based on artificial neural network (ANN) is developed to estimate rotor's position and speed of induction motor. Developed sensorless scheme is a new model reference adaptive system (MRAS) speed observer for direct power control induction motor drives. The proposed MRAS speed observer uses the current model as an adaptive model. The neural network has been then designed and trained online by employing a back propagation network (BPN) algorithm. The estimator was designed and simulated in Simulink. Some simulations are carried out for the closed-loop speed control systems under various load conditions to verify the proposed methods. Simulation results confirm the performance of ANN based sensorless DPC induction motor drive in various conditions.
\end{abstract}

\section{Introduction}

The electrical drive system is used to control the position, speed, and torque of the electric motors. Many works have been done on power converter topologies, control scheme of the electric drive systems, and the motor types in order to enhance and improve the performance of the electric motors so as to exactly perform and do what is required [1]. Induction motors (IMs) are widely used in industrial, commercial, and domestic applications as they are simple, rugged, and easy to maintain and of low cost. Since IMs demand well control performances, precise and quick torque and flux response, large torque at low speed, and wide speed range, the drive control system is necessary for IMs [2].

Control of induction motors can be done using various techniques. Most common techniques are (a) constant voltage/frequency control $(V / F)$, (b) field orientation control (FOC), and (c) direct torque control (DTC). The first one is considered as scalar control since it adjusts only magnitude and frequency of the voltage or current with no concern about the instantaneous values of motor quantities. It does not require knowledge of parameters of the motor, and it is an open-loop control. Thus, it is a low cost simple solution for low performance applications such as fans and pumps. The other two methods are in the space vector control category because they utilize both magnitude and angular position of space vectors of motor variables, such as the voltage and flux. They are employed in high performance applications, such as positioning drives or electric vehicles $[3,4]$.

Direct power control is a control method that directly selects output voltage vector states based on the power and flux errors using hysteresis controllers and without using current loops. In this respect, it is similar to the wellknown direct torque control (DTC) method described in the literatures for various AC motors [5]. What is in common among these applications is that they all are power output devices needed to provide real power to the load. DPC technique has been basically applied to the generators, but it is tried to use it for control of electrical motors instead of DTC technique, due to the problems of torque estimation and dependency on the motor's parameters. Therefore, DPC technique enjoys all advantages of DTC such as fast dynamic and ease of implementation, without having the DTC's problems. However, publications about direct power control 


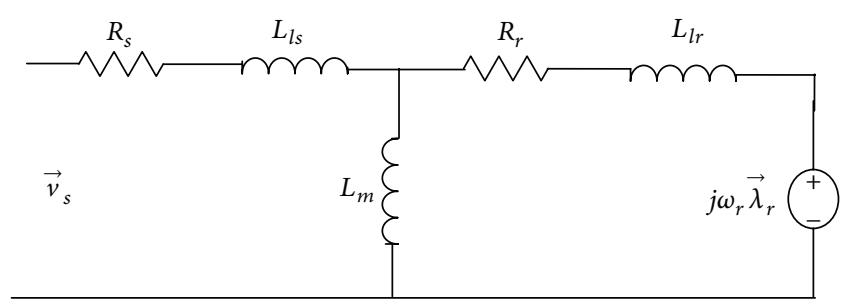

FIGURE 1: The equivalent circuit of IM in the stationary reference frame.

are mainly aimed at either rectifiers [6], converters [7, 8], dual-fed induction generators (DFIG) $[9,10]$, or permanent magnet synchronous generators (PMSG) [11, 12], and there is no research on using the DPC technique for induction motor.

Recently, many researches have been carried on the design of speed-sensorless control schemes of induction motor drives. The main reasons for the development of sensorless drives are reduction of complex hardware and hence cost; increase in mechanical robustness and hence overall ruggedness; working under hostile environment; higher reliability; reduced maintenance; and so forth. Techniques range from open-loop, low performance strategy to closed-loop, high performance over the past decades [13-17].

Speed estimator employing artificial neural network (ANN) is an improvement over the classical mathematical model based approaches [18-23]. It is a major advantage of ANN based techniques that they do not require any mathematical model of the motor under consideration and the drive development time can be substantially reduced. In this study, a speed estimator, based on ANN based model reference adaptive system (MRAS), has been studied and analyzed. For ANN, the back propagation network (BPN) algorithm is used for online training to estimate the motor speed. The paper is organized as follows. Section 2 gives the dynamic model of induction motor. Section 3 proposes the original DPC strategy and employs it for induction motor. Speed estimation technique using neural network is presented in Section 4. Simulation results are presented in Section 5, and the conclusion is given in Section 6 .

\section{Model of Induction Motor}

Neglecting the motor core loss, the saturation, the slot effect, and so forth, the equivalent circuit of the IM in stationary reference frame is shown in Figure 1.

The mathematical model in stationary reference frame can be derived from the equivalent circuit, as follows:

$$
\begin{gathered}
\vec{V}_{s}=R_{s} \vec{i}_{s}+\frac{d \vec{\lambda}_{s}}{d t}, \\
\overrightarrow{0}=R_{r} \vec{i}_{r}+\frac{d \vec{\lambda}_{r}}{d t}-j \omega_{r} \vec{\lambda}_{r},
\end{gathered}
$$

where

$$
\begin{gathered}
L_{s}=L_{l s}+L_{m}, \\
L_{r}=L_{l r}+L_{m}, \\
\vec{\lambda}_{s}=L_{s} \vec{i}_{s}+L_{m} \vec{i}_{r}, \\
\vec{\lambda}_{r}=L_{r} \vec{i}_{r}+L_{m} \vec{i}_{s} .
\end{gathered}
$$

The electromagnetic torque produced in the motor is

$$
T_{e}=\frac{2}{3} p \operatorname{Im}\left(\vec{i}_{s} \vec{\lambda}_{s}^{*}\right),
$$

where $p$ is number of motor pole pairs and $*$ is conjugate operator.

The induction motor model in the $\alpha-\beta$ fixed reference frame can be described by the following equations:

$$
\begin{gathered}
{\left[\begin{array}{c}
u_{\alpha s} \\
u_{\beta s} \\
0 \\
0
\end{array}\right]} \\
=\left[\begin{array}{cccc}
R_{s}+L_{s} p & 0 & L_{m} p & 0 \\
0 & R_{s}+L_{s} p & 0 & L_{m} p \\
L_{m} p & \omega_{r} L & R_{r}+L_{r} p & \omega_{r} L \\
-\omega_{r} L & L_{m} p & -\omega_{r} L & R_{r}+L_{r} p
\end{array}\right] \\
\\
\cdot\left[\begin{array}{c}
i_{\alpha s} \\
i_{\beta s} \\
i_{\alpha r} \\
i_{\beta r}
\end{array}\right], \\
{\left[\begin{array}{c}
\psi_{\alpha s} \\
\psi_{\beta s} \\
\psi_{\alpha r} \\
\psi_{\beta r}
\end{array}\right]=\left[\begin{array}{cccc}
L_{s} & 0 & L_{m} & 0 \\
0 & L_{s} & 0 & L_{m} \\
L_{m} & 0 & L_{r} & 0 \\
0 & L_{m} & 0 & L_{r}
\end{array}\right]\left[\begin{array}{c}
i_{\alpha s} \\
i_{\beta s} \\
i_{\alpha r} \\
i_{\beta r}
\end{array}\right],}
\end{gathered}
$$

where the subscripts $s$ and $r$ stand for stator and rotor quantities; $u$ and $i$ denote voltage and current, respectively; $R$ denotes resistance and $\omega_{r}$ is the rotor speed; $\psi$ denotes flux linkage.

\section{Direct Power and Flux Control of Induction Motors}

The direct power control methods discussed in this paper bear certain similarity to the direct torque control (DTC). Therefore, DPC is actually direct power and flux control, with two parameters involved in the control strategy, so it is also named as direct power and flux control (DPFC) in some publications [24]. Direct power and flux control (DPFC) of IMs is a control method that directly selects output voltage vector states based on the power and flux errors using hysteresis controllers. Figure 2 shows the block diagram of a general open-loop DPFC system. 


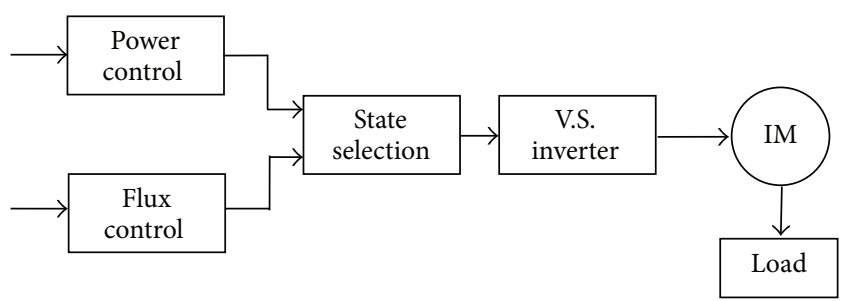

FigURE 2: General block diagram of direct power and flux control system.

3.1. Flux Control Principles. Fixed linkage flux can provide enough electromagnetic torque and avoid magnetizing current saturation in the iron core of the IM. Therefore, in direct torque and flux control, as well as in the proposed direct power and flux controls in the subsequent chapters, the flux is maintained constant [25]. In the stator stationary reference frame, the frame rotation speed is zero and the rotor voltage is zero as well (for squirrel-cage IMs). Thus

$$
\begin{gathered}
\vec{V}_{s}=R_{s} \vec{i}_{s}+\frac{d \vec{\lambda}_{s}}{d t}, \\
\overrightarrow{0}=R_{r} \vec{i}_{r}+\frac{d \vec{\lambda}_{r}}{d t}-j \omega_{r} \vec{\lambda}_{r} .
\end{gathered}
$$

With neglecting the small voltage drop across the stator resistance, we have

$$
\vec{V}_{s} \cong \frac{d \vec{\lambda}_{s}}{d t}
$$

Integrating (7) and writing it in a discrete form, we obtain

$$
\vec{\lambda}_{s}\left(t_{n+1}\right)=\vec{\lambda}_{s}\left(t_{n}\right)+\vec{V}_{s} \Delta t
$$

That is,

$$
\Delta \vec{\lambda}_{s} \cong \vec{V}_{s} \Delta t
$$

where $\Delta t=t_{n+1}-t_{n}$ equals the switching interval. Therefore, within a switching interval $\Delta t$, the increase of stator flux is proportional to the stator voltage space vector. This is the principle of direct flux control in DPC.

3.2. Power Control Principles. From the power flow charts in induction motor, it is evident that real output power is the part that produces the torque and is what the user of the system is mostly interested in. The output real power is given by

$$
\begin{gathered}
P_{\text {out }}=T_{e} \omega_{m}=T_{e} \frac{\omega_{r}}{p} \\
T_{e}=\frac{2}{3} p \operatorname{Im}\left(\vec{i}_{s} \vec{\lambda}_{s}^{*}\right)=\frac{2}{3} p \operatorname{Im}\left(\frac{L_{r} \vec{\lambda}_{s}-L_{m} \vec{\lambda}_{r}}{L_{s} L_{r}-L_{m}^{2}} \vec{\lambda}_{s}^{*}\right) \\
=-\frac{2}{3} p \frac{L_{m}}{L_{\sigma}^{2}} \operatorname{Im}\left(\vec{\lambda}_{r} \vec{\lambda}_{s}^{*}\right)=\frac{2}{3} p \frac{L_{m}}{L_{\sigma}^{2}} \operatorname{Im}\left(\vec{\lambda}_{s} \vec{\lambda}_{r}^{*}\right) \\
=\frac{2}{3} p \frac{L_{m}}{L_{\sigma}^{2}} \lambda_{s} \lambda_{r} \sin \left(\theta_{s}-\theta_{r}\right) .
\end{gathered}
$$

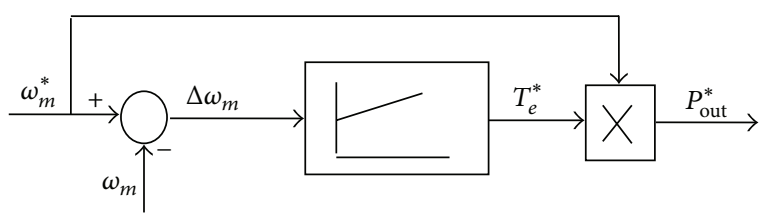

Figure 3: Generating the output power reference obtained from speed loop.

Substituting the torque in (10) with (11), the output power becomes

$$
P_{\text {out }}=\frac{2}{3} \omega_{r} \frac{L_{m}}{L_{\sigma}^{2}} \operatorname{Im}\left(\vec{\lambda}_{s} \vec{\lambda}_{r}^{*}\right)=\frac{2}{3} \frac{L_{m}}{L_{\sigma}^{2}} \omega_{r} \lambda_{s} \lambda_{r} \sin \left(\theta_{s}-\theta_{r}\right) .
$$

Since the magnitude of the stator flux is kept constant and the rotor flux does not change much due to its inertia, the rotor speed and angle can be considered constant too. The formula above shows that the change of output power depends only on the change of stator flux angle. The stator voltage vector that can increase the stator angle needs to be raised in order to increase the output power. The real output power equation obtained above is only valid for explanation of the principles of power control. However, it is not appropriate for the purpose of estimating the actual power in simulations.

3.3. Output Power Reference. The output power reference is the command value, or set point, for the power control. In a closed-loop speed control system, the reference of the power controller is obtained from the output of the PI-type speed controller (see Figure 3). The speed error is defined as the difference of the reference speed and the estimated actual speed:

$$
\Delta \omega_{m}=\omega_{m}^{*}-\omega_{m},
$$

where $\omega_{m}^{*}$ is the reference speed (the asterisk denotes a reference value). Then, the reference torque can be obtained through a conventional PI controller as

$$
T_{e}^{*}=K_{p}\left(\Delta \omega_{m}\right)+K_{i} \int\left(\Delta \omega_{m}\right) d t .
$$

The continuous standard form above can also be expressed in a discrete incremental PI control form, which is more suitable for the digital implementation:

$$
\begin{aligned}
T_{e}^{*}\left(t_{n+1}\right)= & T_{e}^{*}\left(t_{n}\right)+K_{p}\left[\Delta \omega_{m}\left(t_{n}\right)-\Delta \omega_{m}\left(t_{n-1}\right)\right] \\
& +K_{i} \Delta T \Delta \omega_{m}\left(t_{n}\right) .
\end{aligned}
$$

The subscript $(n)$ denotes the current sampling instant, $(n-1)$ is the last instant, and $(n+1)$ is the next one. The proportional gain is denoted by $K_{p}, K_{i}$ is the integral gain, which equals $K_{p}$ divided by the integral time constant $T_{i}$, and $\Delta T$ is the sampling time interval between the $n$ and $(n+1)$ sampling instants. The output power reference according to (10) is therefore expressed as

$$
P_{\mathrm{out}}^{*}=T_{e}^{*} \omega_{m}^{*}
$$


TABLE 1: Combination of the power and flux controller outputs.

\begin{tabular}{lcc}
\hline$b_{p}=-1$ & $b_{p}=0$ & $b_{p}=1$ \\
\hline 1 & 2 & 3 \\
4 & 5 & 6 \\
\hline
\end{tabular}

The process of obtaining the output power reference from the speed reference is illustrated in Figure 3. For simulations, the actual motor speed $\omega_{m}$ can be obtained as

$$
\omega_{m}=\frac{1}{J} \int\left(T_{e}-T_{l d}\right) d t
$$

In practice the speed is either measured directly or estimated from the current and voltage signals. The magnitude of the stator flux is kept constant in the simulation; thus the flux reference $\lambda_{s}^{*}$ is a constant. The error of the stator flux is

$$
\Delta \lambda_{s}=\lambda_{s}^{*}-\lambda_{s}
$$

3.4. Power and Flux Hysteresis Controllers. Both the output power and the stator flux controllers are of hysteresis type. Depending on the control error, the output of the controller is set to two or three discrete values. The power controller has a three-level output $[24,26]$. The values are 1,0 , and -1 , representing an increase, no change, and a decrease of the controlled variable, respectively. The number of flux controller output levels is two, with 1 and 0 meaning increase and decrease commands, respectively. Figure 4 illustrates characteristics of these two controllers.

3.5. Switching Table. The task of the state selector in the direct power control is to combine the outputs of the power controller and flux controller to select the values of the switching variables $a, b$, and $c$. These variables describe the required voltage vectors of the inverter. To make it easier to implement, the combination of the two controller outputs can be expressed as follows:

$$
b=3 b_{\lambda}+b_{p}+2 .
$$

In the above equation, variable $b=1,2,3,4,5,6$, while $b_{\lambda}=$ $(0,1)$ and $b_{p}=(-1,0,1)$.

Alternatively, (19) can also be represented by Table 1 .

A whole stator flux cycle of $360^{\circ}$ is divided equally into 6 sectors, each one spanning $60^{\circ}$. Combining with the sector numbers from 1 through 6 produces lookup Table 2 for the state selection [24]. The concept of state selection is illustrated in Figure 5.

Note that the stator flux angle $\theta_{s}$ must be converted to a sector number from 1 through 6 for the use of Table 2 for state selection.

3.6. Estimation of Stator Flux and Output Power. The estimation of flux is implemented by integration of (5):

$$
\vec{\lambda}_{s}=\int\left(\vec{v}_{s}-\vec{i}_{s} R_{s}\right) d t
$$

TABLE 2: State selection lookup table.

\begin{tabular}{lcccccc}
\hline & $b=1$ & $b=2$ & $b=3$ & $b=4$ & $b=5$ & $b=6$ \\
\hline Sector 1 & 1 & 0 & 2 & 5 & 7 & 6 \\
Sector 2 & 5 & 7 & 6 & 4 & 0 & 2 \\
Sector 3 & 4 & 0 & 1 & 6 & 7 & 3 \\
Sector 4 & 6 & 7 & 5 & 2 & 0 & 1 \\
Sector 5 & 2 & 0 & 4 & 3 & 7 & 5 \\
Sector 6 & 3 & 7 & 6 & 1 & 0 & 4 \\
\hline
\end{tabular}

That output power can be calculated from (10). Figure 6 illustrates the estimation of actual output power and flux from stator voltage and current together with mechanical angular speed. These estimated values are the feedback for the output power and stator flux controls.

\section{Speed Estimation Using Neural Network}

In MRAS technique, some state variables, $X_{d}$ and $X_{q}$ (e.g., rotor flux linkage components, $\psi_{d r}$ and $\psi_{q r}$, or back-EMF components, $e_{d}, e_{q}$, etc.), of the induction machine (which are obtained by using measured quantities, e.g., stator voltages and currents) are estimated in a reference model and are then compared with state variables $\widehat{X}_{d}$ and $\widehat{X}_{q}$ estimated by using an adaptive model. The difference between these state variables is then formulated into a speed tuning signal $(\varepsilon)$, which is then an input into an adaptation mechanism, which outputs the estimated rotor speed $(\widehat{\omega})$.

Speed estimator using ANN is a part of a model reference adaptive system (MRAS), where ANN takes the role of the adaptive model. ANN contains the adjustable and constant weights and the adjustable weights are proportional to the rotor speed. The adjustable weights are changed by using the error between the outputs of the reference and adaptive model. Figure 7 shows the MRAS-based speed estimation scheme, which contains an ANN with BPN adaptation technique [17].

The outputs of the reference model are the rotor flux linkage components in stationary reference frame, given by

$$
\begin{aligned}
& \psi_{d r}=\frac{L_{r}}{L_{m}}\left[\int\left(v_{d s}-R_{S} i_{d s}\right) d t-L_{s}^{\prime} i_{d s}\right], \\
& \psi_{q r}=\frac{L_{r}}{L_{m}}\left[\int\left(v_{q s}-R_{S} i_{q s}\right) d t-L_{s}^{\prime} i_{q s}\right] .
\end{aligned}
$$

These two equations do not contain the rotor speed and describe the reference model. The equations of adaptive model are given by

$$
\begin{aligned}
& \widehat{\psi}_{d r}=\frac{1}{T} \int\left(L_{m} i_{d s}-\widehat{\psi}_{d r}-\omega_{r} T_{r} \widehat{\psi}_{q r}\right) d t, \\
& \widehat{\psi}_{q r}=\frac{1}{T} \int\left(L_{m} i_{q s}-\widehat{\psi}_{q r}-\omega_{r} T_{r} \widehat{\psi}_{d r}\right) d t .
\end{aligned}
$$

It is possible to implement (22) by a two-layer ANN containing weights $W_{1}(=1-C), W_{2}\left(=\omega_{r} T_{r} C\right)$, and $W_{3}\left(=C l_{m}\right)$; that $C=T / T_{r} ; T, T_{r}$ are sampling time and rotor time 


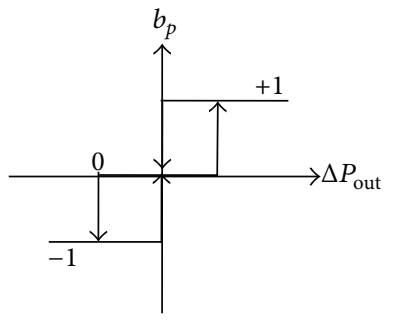

(a)

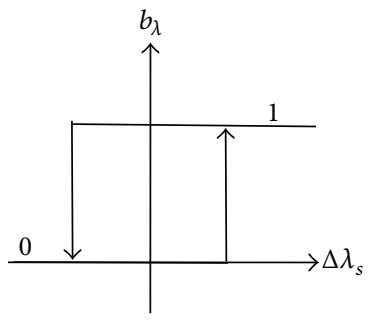

(b)

FIgURE 4: Characteristics of the hysteresis controllers: (a) power controller and (b) flux controller.

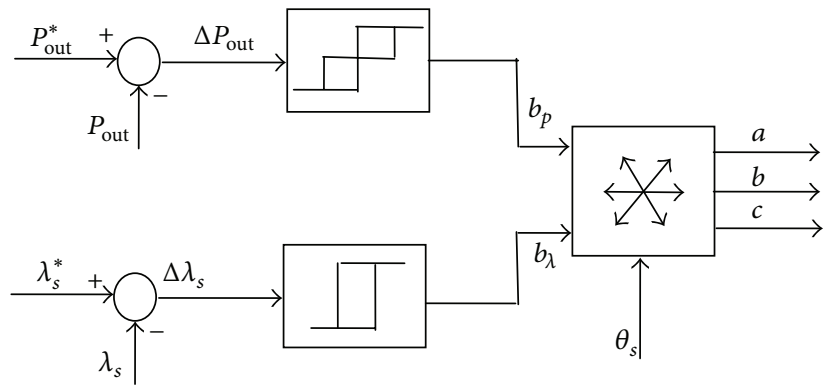

FIGURE 5: Block diagram of the inverter state selection.

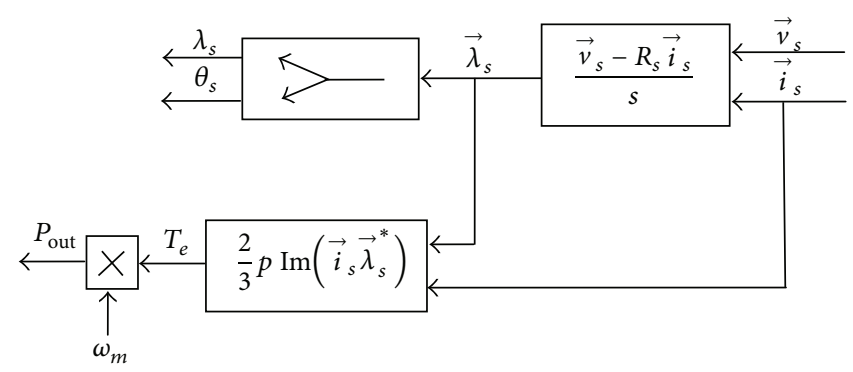

FIGURE 6: Estimation of actual output power and stator flux linkage.

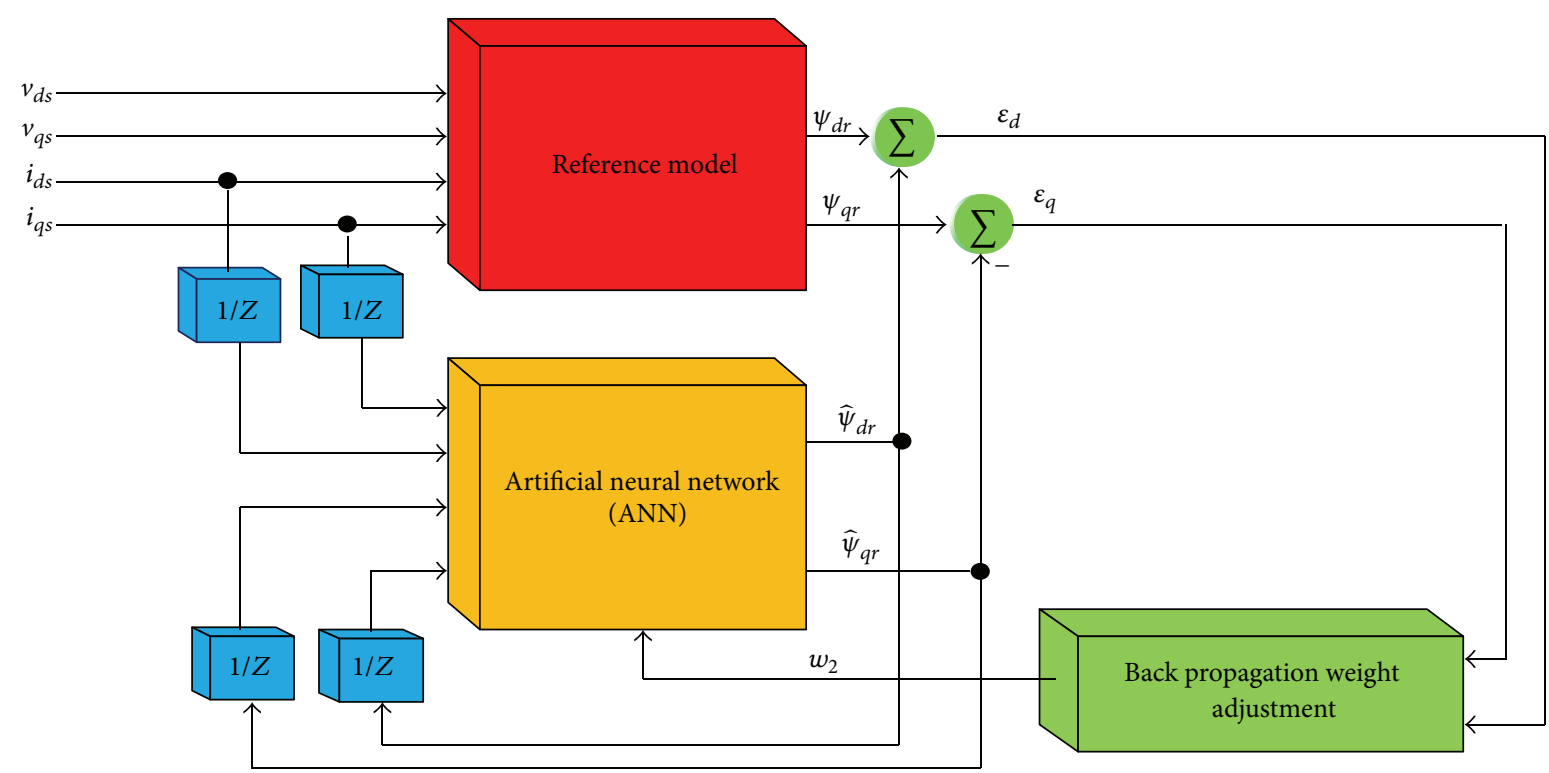

FIgURE 7: MRAS-based rotor speed estimator using ANN. 


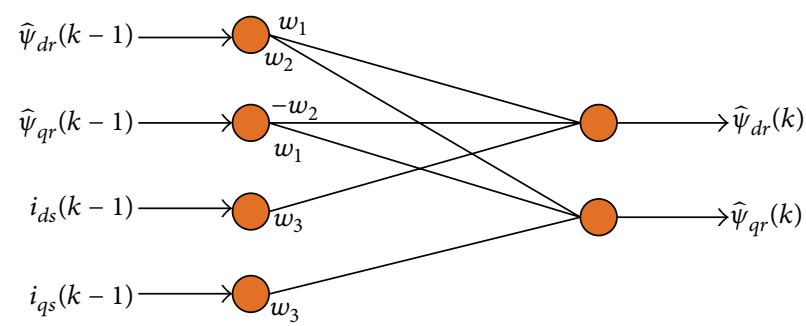

FIGURE 8: ANN model for the estimation of rotor flux linkage.

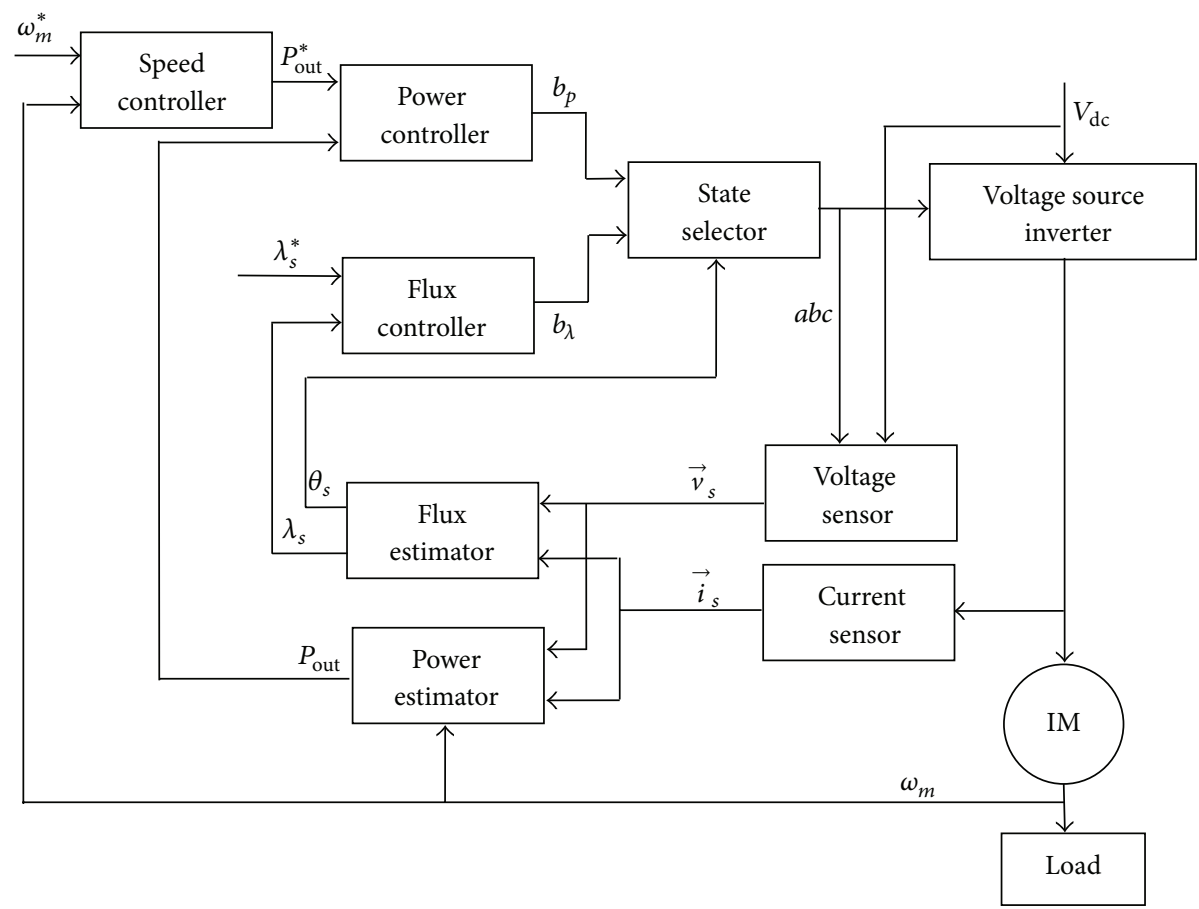

FIGURE 9: Block diagram of direct output power and flux control system for IM for closed-loop speed control.

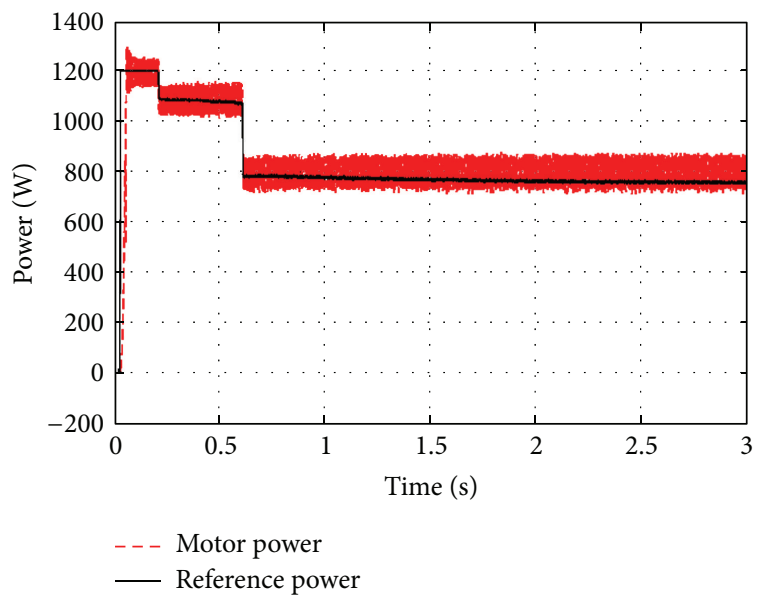

(a)

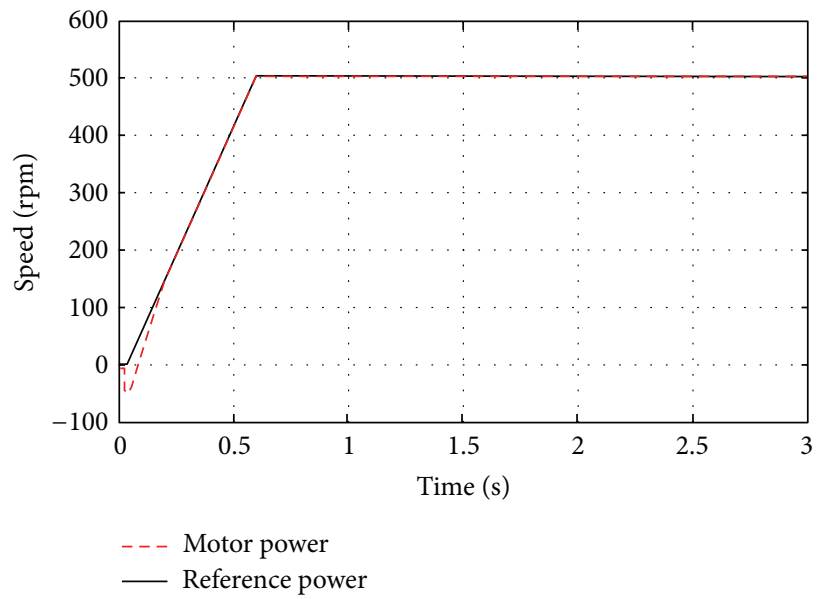

(b)

FIGURE 10: Simulation results DPC of induction motor: (a) electromagnetic power and (b) rotor speed. 


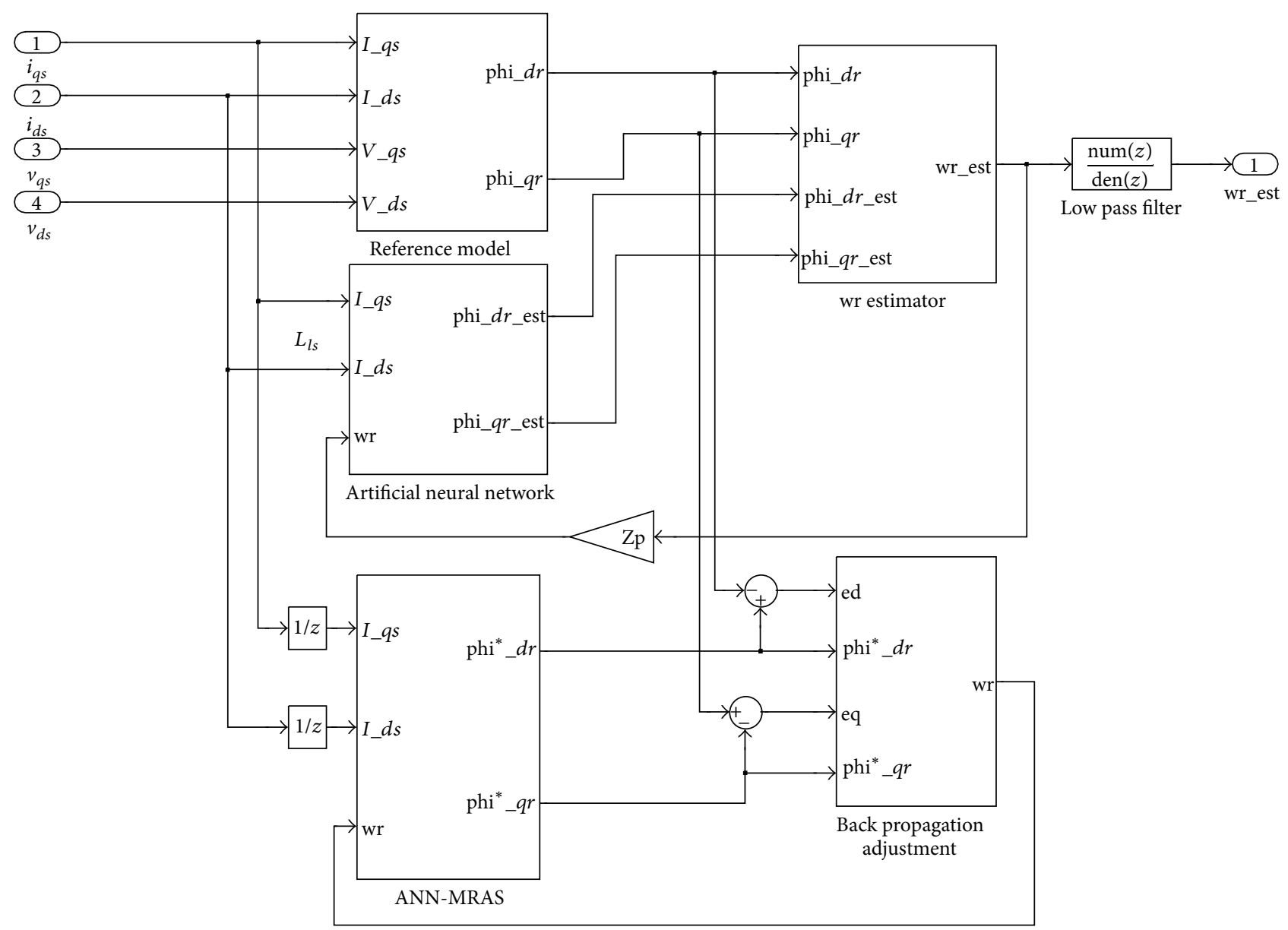

FIGURE 11: ANN based model of speed estimation.

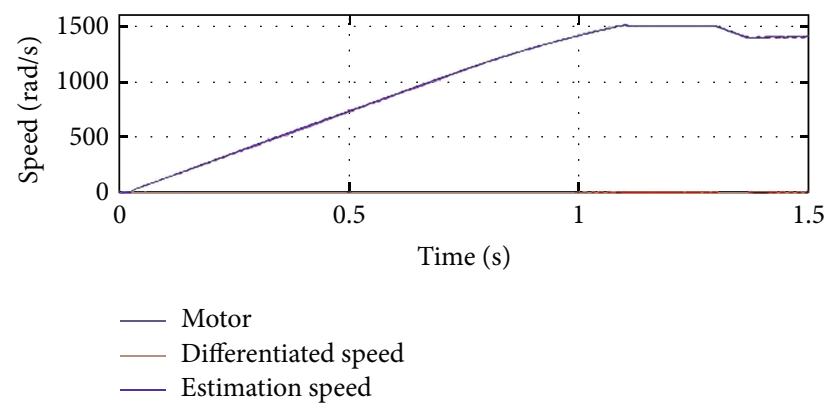

FIGURE 12: Response comparison of actual machine and ANN based speed estimator with error.

constant. The variable ANN weight $W_{2}$ is proportional to the rotor speed. By using the backward difference method, the equation of adaptive model is given below:

$$
\begin{aligned}
& \widehat{\psi}_{d r}(k)=W_{1} \widehat{\psi}_{d r}(k-1)-W_{2} \widehat{\psi}_{q r}(k-1)+W_{3} i_{d s}(k-1) \\
& \widehat{\psi}_{q r}(k)=W_{1} \widehat{\psi}_{q r}(k-1)-W_{2} \widehat{\psi}_{d r}(k-1)+W_{3} i_{q s}(k-1)
\end{aligned}
$$

which gives the value of rotor flux at the $K$ th sampling instant. These equations can be visualized by the very simple twolayer ANN shown in Figure 8.

After taking learning factor $\eta$ and momentum term $\alpha$ into account, the estimated rotor speed is given below:

$$
\begin{aligned}
\widehat{\omega}_{r}(k) & \\
= & \widehat{\omega}_{r}(k-1) \\
& +\frac{\eta}{T}\left\{\begin{array}{l}
-\left[\psi_{d r}(k)-\widehat{\psi}_{d r}(k)\right] \widehat{\psi}_{q r}(k-1) \\
+\left[\psi_{q r}(k)-\widehat{\psi}_{q r}(k)\right] \widehat{\psi}_{d r}(k-1)
\end{array}\right\} \\
& +\frac{\alpha}{T} \Delta w_{2}(k-1) .
\end{aligned}
$$

If the value of learning rate $(\eta)$ is chosen high, it may lead to oscillations in the outputs of ANN, and $\alpha$ is chosen in range between 0.1 and 0.8 . The inclusion of momentum term into the weight adjustment mechanism can significantly increase the convergence, which is extremely useful when the ANN shown in Figure 8 is used to estimate in real time [13]. 


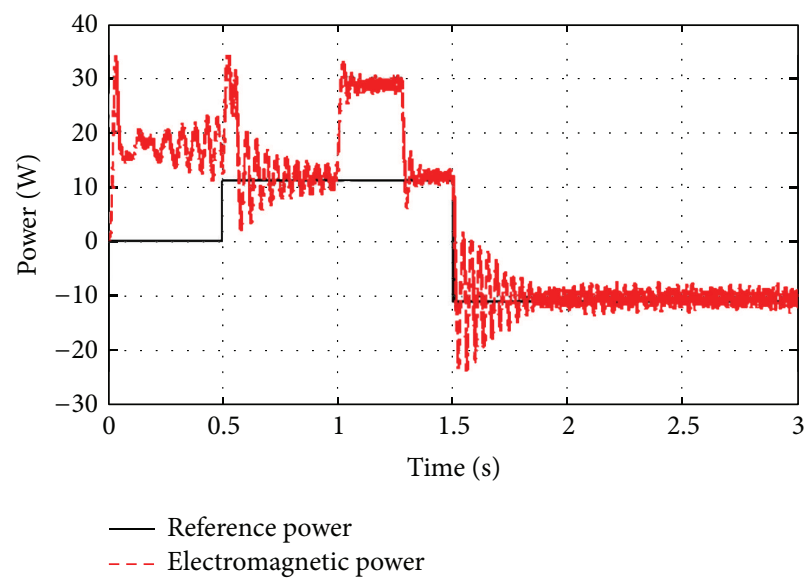

(a)

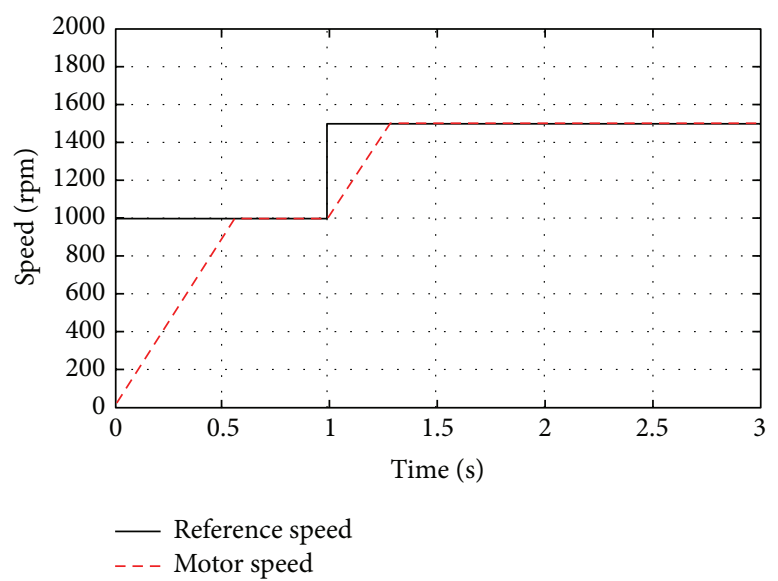

(b)

FIGURE 13: Simulation results of DPC based on ANN of induction motor: (a) electromagnetic power and (b) rotor speed.

TABLE 3: Induction motor parameter.

\begin{tabular}{lc}
\hline Parameter & Value \\
\hline$P_{n}$ & $2 \mathrm{hp}$ \\
$\omega_{\text {rated }}$ & $1500[\mathrm{rpm}]$ \\
$V$ & $300[\mathrm{~V}]$ \\
$I_{n}$ & $2.1[\mathrm{~A}]$ \\
$J$ & $0.004\left[\mathrm{~kg} \cdot \mathrm{m}^{2}\right]$ \\
$p$ & 2 \\
$R_{s}$ & $10[\Omega]$ \\
$L_{m}$ & $330[\mathrm{mH}]$ \\
$L_{l s}, L_{l r}$ & $0.4[\mathrm{mH}]$ \\
$B$ & $0.002[\mathrm{~N} \cdot \mathrm{m} /(\mathrm{rad} / \mathrm{sec})]$ \\
\hline
\end{tabular}

\section{Simulation Results}

5.1. Direct Power Control. The simulation is carried out using MATLAB. The whole system setup is shown in Figure 9. It contains the power and flux controllers as inner loops and the speed loop as outer loop.

The sampling frequency is chosen as $50 \mathrm{kHz}$. The hysteresis tolerance for both power and flux controller is $1 \%$ of respective reference values. For the PI speed controller (see (14)), the proportional gain is tuned to $k_{p}=90$; the overall coefficient of the integral part is set to 0.1 , which yielded an integral gain $k_{i}=5000$ at the $50 \mathrm{kHz}$ sampling rate. The reference speed profile is set in which the speed always remains below the rated speed to avoid field weakening. The parameters of IM used in the simulations are listed in Table 3. The simulation results are shown in Figure 10.

5.2. Speed Estimator Based on ANN. Implementation of ANN based speed estimator is carried out in MATLAB/Simulink, as shown in Figure 11.

The response of ANN based speed estimator is compared with actual machine which is shown in Figure 12.
5.3. Direct Power Control with ANN. The result of ANN based speed estimator with DPC controller is shown in Figure 13.

\section{Conclusion}

This paper studies the possibility of direct power control for speed control of induction motor. It has been shown that DPC is basically derived from direct torque control (DTC) method, and the simulation results show that this control scheme for IMs motor has all the advantages of direct torque control method. One of the major advantages of DPC method compared to DTC method is the easier calculation of actual power. Moreover, this paper proposes a new MRAS speed observer for DPC controlled induction motor drives using neural networks for speed estimation. The simulation results show that the proposed two-layers neural network can identify and track the motor speed accurately during the whole operating region. Structure and algorithm are also simple. Overall, the dynamic response of this scheme of speed estimation shows a good performance.

\section{Conflict of Interests}

The authors declare that there is no conflict of interests regarding the publication of this paper.

\section{References}

[1] P. C. Krause, O. Wasynozuk, and S. D. Sudhoff, Analysis of Electric Machinery and Drive Systems, IEEE Press, 2nd edition, 2002.

[2] I. Boldea and S. A. Nasar, Electric Drives, Taylor \& Francis, New York, NY, USA, 2006.

[3] P. Vas, The Control of AC Machines, Oxford University Press, New York, NY, USA, 1990.

[4] A. M. Trzynadlowski, Control ofInduction Motors, Academic press, 2001. 
[5] G. S. Buja and M. P. Kazmierkowski, "Direct torque control of PWM inverter-fed AC motors-a survey," IEEE Transactions on Industrial Electronics, vol. 51, no. 4, pp. 744-757, 2004.

[6] G. Escobar, A. M. Stanković, J. M. Carrasco, E. Galván, and R. Ortega, "Analysis and design of direct power control (DPC) for a three phase synchronous rectifier via output regulation subspaces," IEEE Transactions on Power Electronics, vol. 18, no. 3, pp. 823-830, 2003.

[7] S. Vazquez, J. A. Sanchez, J. M. Carrasco, J. I. Leon, and E. Galvan, "A model-based direct power control for three-phase power converters," IEEE Transactions on Industrial Electronics, vol. 55, no. 4, pp. 1647-1657, 2008.

[8] Z. Dawei, X. Lie, and B. W. Williams, "Improved direct power control of grid-connected DC/AC converters," IEEE Transactions on Power Electronics, vol. 24, no. 5, pp. 1280-1292, 2009.

[9] L. Xu and P. Cartwright, "Direct active and reactive power control of DFIG for wind energy generation," IEEE Transactions on Energy Conversion, vol. 21, no. 3, pp. 750-758, 2006.

[10] D. Zhi and L. Xu, "Direct power control of DFIG with constant switching frequency and improved transient performance," IEEE Transactions on Energy Conversion, vol. 22, no. 1, pp. 110118, 2007.

[11] Y. Errami, M. Benchagra, M. Hilal, M. Maaroufi, and M. Ouassaid, "Control strategy for PMSG wind farm based on MPPT and direct power control," in Proceedings of the International Conference on Multimedia Computing and Systems (ICMCS '12), pp. 1125-1130, May 2012.

[12] A. Harrouz, A. Benatiallah, and O. Harrouz, "Direct power control of a PMSG dedicated to standalone wind energy systems," in Proceedings of the 8th International Conference and Exhibition on Ecological Vehicles and Renewable Energies (EVER '13), pp. 1-5, March 2013.

[13] P. Vas, Sensorless Vector and Direct Torque Control, Oxford University Press, 1998.

[14] K. Sedhuraman, S. Himavathi, and A. Muthuramalingam, "Performances comparison of neural architectures for on-line speed estimation in sensorless IM drives," World Academy of Science, Engineering and Technology, no. 60, pp. 1318-1325, 2011.

[15] S. Meziane and R. Benalla, "MRAS based speed control of sensorlessinduction motor drives," ICGST-ACSE Journal, vol. 7, no. 1, pp. 43-500, 2007.

[16] E. Levi and M. Wang, "Impact of parameter variations on speed estimation in sensorless rotor flux oriented induction machines," in Proceedings of the 7th International Conference on Power Electronics and Variable Speed Drives, pp. 305-310, London, UK, September 1998.

[17] M. E. Elbulk, L. Tong, and I. Husain, "Neural-network-based model reference adaptive systems for high-performance motor drives and motion controls," IEEE Transactions on Industry Applications, vol. 38, no. 3, pp. 879-886, 2002.

[18] M. T. Hagan, B. Demuth, and M. Beale, Neural Network Design, Cengage Learning Pvt Ltd, New Delhi, India, 2008.

[19] S.-H. Kim, T.-S. Park, J.-N. Yoo, and G.-T. Park, "Speedsensorless vector control of an induction motor using neural network speed estimation," IEEE Transactions on Industrial Electronics, vol. 48, no. 3, pp. 609-614, 2001.

[20] M. Kuchar, P. Brandstetter, and M. Kaduch, "Sensorless induction motor drive with neural network," in Proceedings of the IEEE 35th Annual Power Electronics Specialists Conference (PESC '04), pp. 3301-3305, June 2004.
[21] S. Maiti, V. Verma, C. Chakraborty, and Y. Hori, "An adaptive speed sensorless induction motor drive with artificial neural network for stability enhancement," IEEE Transactions on Industrial Informatics, vol. 8, no. 4, pp. 757-766, 2012.

[22] P. Girovský and J. Timko, "Shaft sensor-less FOC control of an induction motor using neural estimators," Acta Polytechnica Hungarica, vol. 9, no. 4, pp. 31-45, 2012.

[23] D. P. Kothari and I. J. Nagrath, Electric Machines, chapter 9, Tata McGraw-Hill Education Private Limited, 2004.

[24] G. Escobar, A. M. Stanković, J. M. Carrasco, E. Galván, and R. Ortega, "Analysis and design of direct power control (DPC) for a three phase synchronous rectifier via output regulation subspaces," IEEE Transactions on Power Electronics, vol. 18, no. 3, pp. 823-830, 2003.

[25] N. R. N. Idris and A. H. M. Yatim, "Direct torque control of induction machines with constant switching frequency and reduced torque ripple," IEEE Transactions on Industrial Electronics, vol. 51, no. 4, pp. 758-767, 2004.

[26] S.-H. Huh, K.-B. Lee, D.-W. Kim, I. Choy, and G.-T. Park, "Sensorless speed control system using a neural network," International Journal of Control, Automation and Systems, vol. 3, no. 4, pp. 612-619, 2005. 

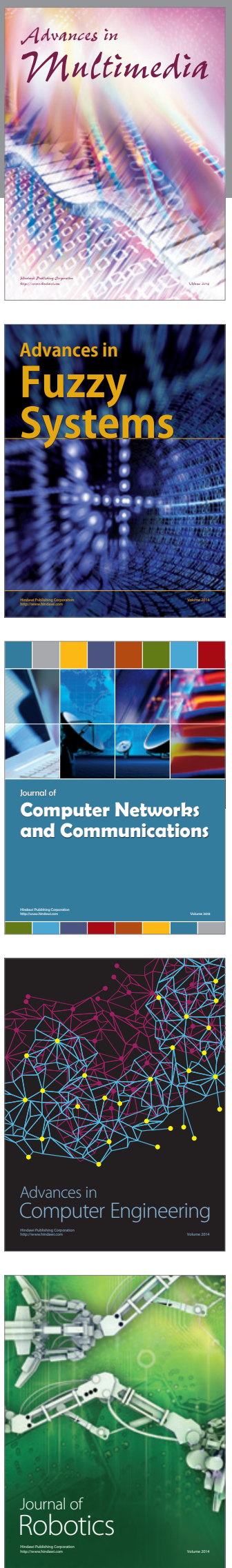

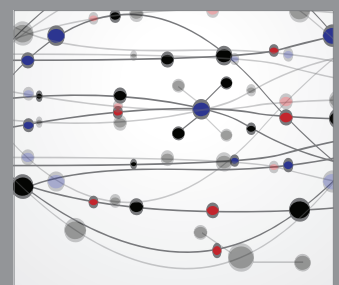

The Scientific World Journal
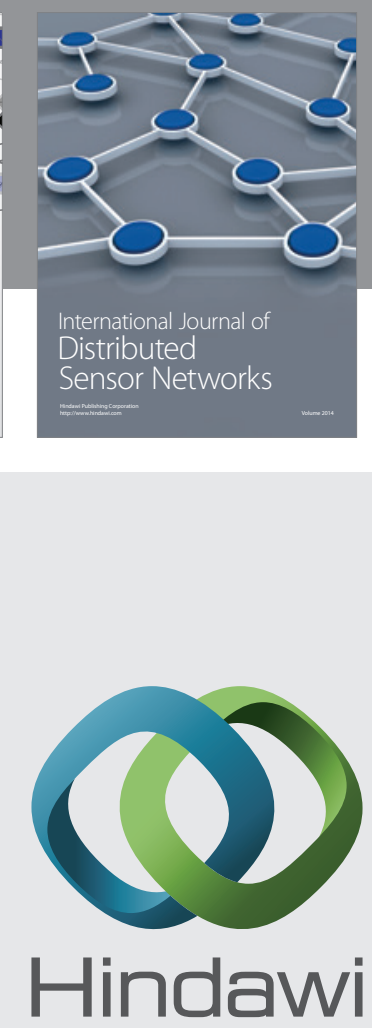

Submit your manuscripts at

http://www.hindawi.com
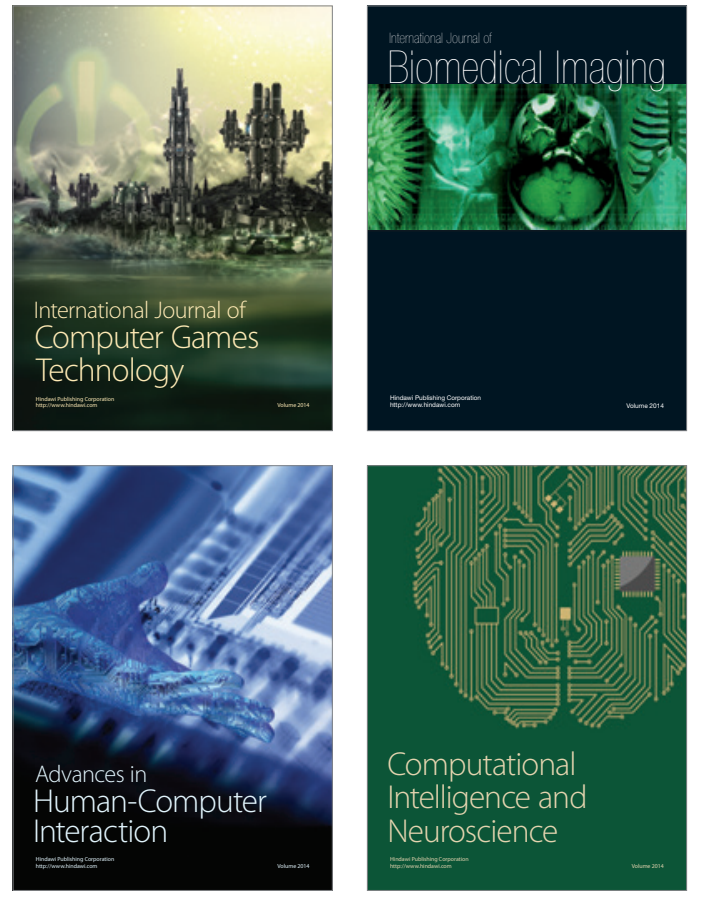
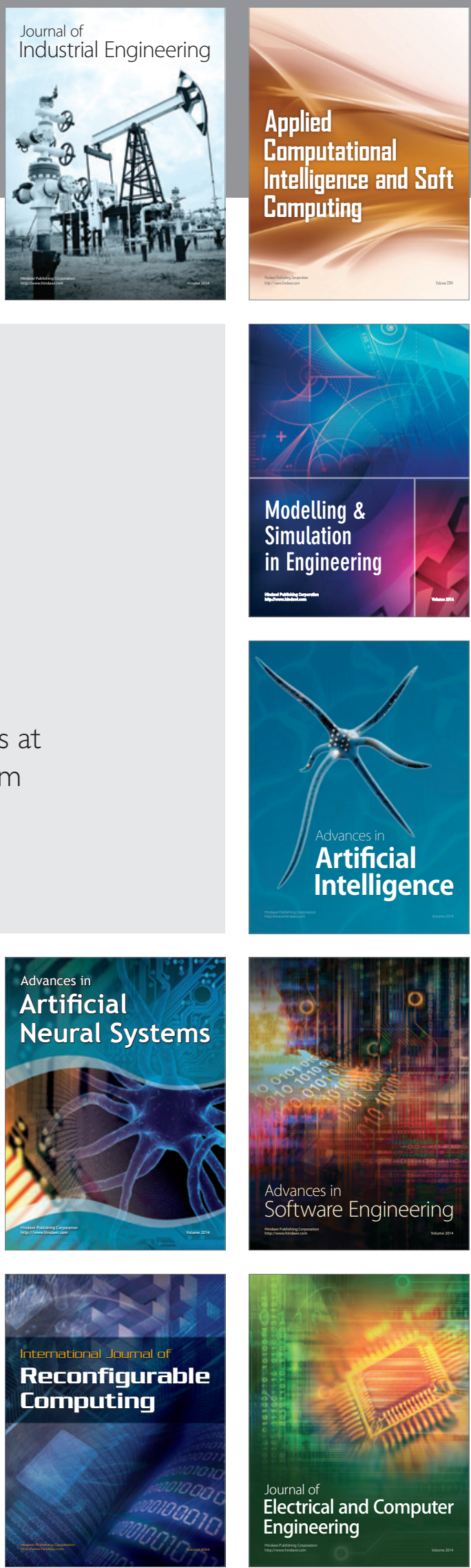